\title{
A clinical heritage of empirical research. In memory of Jeremy Safran
}

\author{
Vittorio Lingiardi, Daniela Gentile \\ Department of Dynamic and Clinical Psychology, Faculty of Medicine and Psychology, Sapienza University of Rome, Rome, Italy
}

This is Part II of a special issue, Research in Psychotherapy: Psychopathology, Process and Outcome, dedicated in memory of our colleague Jeremy Safran (Part I was published in April 2019). For a recollection of the human and professional figure of Jeremy and a contextualization of this special issue in the theoretical, clinical, and research framework on the therapeutic alliance, please refer to our introductory notes in Part I (Lingiardi \& Gentile, 2019).

All of the contributions (theoretical papers, clinical cases, qualitative and quantitative studies) presented in this second part of the special issue focus on the topic of ruptures and resolutions in the therapeutic alliance. Each paper demonstrates a unique approach, perspective, and methodology.

In their introductory paper The sister concepts of the working alliance and the real relationship: on their development, rupture, and repair (2019, pp. 142-149), Gelso and Kline explore areas of agreement with and departure from some of Safran's key conceptualizations on these topics, focusing on overlaps and distinctions. The authors propose a more limited definition of ruptures, suggesting that, whereas ruptures in the working alliance can generally be repaired for the benefit of the work, ruptures in the real relationship are likely to be more damaging to the treatment.

Correspondence: Vittorio Lingiardi, Department of Dynamic and Clinical Psychology, Faculty of Medicine and Psychology, Sapienza University of Rome, Via dei Marsi 78, 00185 Rome, Italy. E-mail: vittorio.lingiardi@uniroma1.it

Citation: Lingiardi, V., \& Gentile, D. (2019). A clinical heritage of empirical research. In memory of Jeremy Safran. Research in Psychotherapy: Psychopathology, Process and Outcome, 22(2), 139141. doi: 10.4081 /ripppo.2019.416

Key words: Therapeutic alliance; Ruptures and resolutions; Jeremy Safran; Psychotherapy process.

Received for publication: 8 July 2019.

Accepted for publication: 8 July 2019.

This work is licensed under a Creative Commons Attribution NonCommercial 4.0 License (CC BY-NC 4.0).

${ }^{\circ}$ Copyright: the Author(s), 2019

Licensee PAGEPress, Italy

Research in Psychotherapy:

Psychopathology, Process and Outcome 2019; 22:139-141

doi:10.4081/ripppo.2019.416
Other papers presented in this issue explore the relevance of the alliance negotiation with patients with depressive (Doležal et al., 2019, pp. 150-164) and personality disorders (Oasi, Maggio, Pacella, \& Molgora, 2019, pp. 165-174; Zalman, Aafjes-van Doorn, \& Eubanks, 2019, pp. 212-223), with particular reference to the risk of unilateral interruption of treatment. Drop-out represents a significant problem in psychotherapy, in many cases connected to ruptures that are unrecognized or not sufficiently repaired by the clinician. However, repair of the rupture promotes therapeutic change and prevents the risk of impasse and premature interruption of treatment (see, e.g., Eubanks-Carter, Muran, Safran, \& Hayes, 2011; Safran, Muran, \& Eubanks-Carter, 2011). The study by Doležal et al., Why did she leave? Development of working alliance in a case of psychotherapy for depression (2019, pp. 150-164), provides the case of a 23 -year-old female university student treated with short-term dynamic therapy. During the treatment, her symptomatology, quality of life, and social functioning improved. However, despite these therapeutic changes, the patient dropped out and unilaterally cut off contact with her therapist. The authors analyze the ruptures and resolutions in the working alliance demonstrated in three session transcripts to gain insight into the dynamics of the dropout.

As widely documented in the literature, personality disordered patients present major difficulties in constructing and maintaining the therapeutic alliance. Such patients represent a great challenge for clinicians, as evidenced by Safran and Muran's studies (Muran, Safran, Samstag, \& Winston, 2005; Muran et al., 2009; Muran, Segal, Samstag, \& Crawford, 1994) and confirmed by further research (Bender, 2005; Colli, Gentile, Condino, \& Lingiardi, 2019; Smith, Hilsenroth, Fiori, \& Bornstein, 2014; Tanzilli, Colli, Gualco, \& Lingiardi, 2018). In their qualitative study Dropout and narcissism: an exploratory research about situational factors and personality variables of the psychotherapist (2019, pp. 165-174), Oasi, Maggio, Pacella, and Molgora explore the association between some therapist characteristics (narcissistic dimensions) and the premature termination of therapy in a sample of 20 experienced psychotherapists. The subjective experience of the clinicians is investigated with the Impasse Interview, derived from the Questionnaire on Impasse into Individual Therapy (Hill, Nutt-Williams, Heaton, Thompson, \& Rhodes, 1996) and the Hypersensitive Narcissism Scale (Hendin \& Cheek, 1997). Alliance 
challenges in the treatment of a narcissistic patient: the case of Alex (2019, pp. 212-223), by Zalman, Aafjes-van Doorn, and Eubanks, illustrates the clinical case and therapeutic process of a fictional character, Alex, from the TV series In Treatment. The authors evidence the difficulties that clinicians can face in co-constructing an alliance with a narcissistic patient and the frequent episodes of therapy failure and drop-out in this situation.

The therapeutic alliance is also problematic with adolescent patients. The contribution of Fernández González, Pérez, and Krause, in The relation between the therapeutic alliance and communicative intentions in therapeutic interaction during the initial phase of adolescent therapy (2019, pp. 189-198), examines the connection between the therapeutic alliance and adolescent-therapist verbal interaction during the early sessions of treatment, using a micro-process analysis of therapeutic conversations in a sample of 19 patients across 50 conversation segments (2043 adolescent and 3208 therapist speaking turns). The contribution by Shenk et al., Trajectories of alliance ruptures in the psychotherapy of adolescents with borderline personality pathology: timing, typology and significance (2019, pp. 199-211) describes the fluctuation of alliance ruptures and resolutions on a session-by-session basis in a clinical sample of 10 adolescents with borderline personality disorder. A total of 187 sessions are analyzed with a mixed-effect model to identify the specific features of the therapeutic alliance with borderline adolescents.

The experience of the therapeutic relationship can be influenced by different dimensions: personality styles, regulation of intimacy and dependency, anaclitic versus introjective orientation, and attachment representations. The study by Talia, Miller-Bottome, Wyner, Lilliengren, and Bate, Patients' Adult Attachment Interview classification and their experience of the therapeutic relationship: are they associated? (2019, pp. 175-188) investigates whether the pre-treatment Adult Attachment Interview (AAI) ratings of 30 patients with different diagnoses in Brief Relational Therapy (Safran \& Muran, 2000 ) are associated with their narratives in a post-treatment interview about their relationship with the therapist. Results show that the patients' AAI classifications at the beginning of treatment predict the characteristics of the therapeutic relationship at the end of treatment. Specifically, the patients' attachment states of mind influence the ways in which they experience, represent, and communicate about the therapeutic relationship.

Finally, a relevant topic in empirical research on the therapeutic alliance refers to the evaluation of the rupture or repair as it occurs in the psychotherapy session. Since the alliance is determined by a dynamic process of dyadic co-construction, it is important to assess the in-session patient and therapist negotiation. Galvão, Silva, and Vasco (2019, pp. 224-232), with their methodological contribution The Alliance Negotiation Scale: Portuguese adaptation, propose a validation of this 12 -item scale (Alliance
Negotiation Scale, ANS; Doran, Safran, Waizmann, Bolger, \& Muran, 2012). Their study presents the psychometric properties of reliability and validity in the ANS on a Portuguese clinical population of 120 participants.

We thank all the colleagues who contributed to this special issue, remembering Jeremy Safran, the richness of his legacy, and the fruitful influence of his studies for the future generation of clinicians and researchers.

\section{References}

Bender, D. S. (2005). The therapeutic alliance in the treatment of personality disorders. Journal of Psychiatric Practice, 11(2), 73-87.

Colli, A., Gentile, D., Condino, V., \& Lingiardi, V. (2019). Assessing alliance ruptures and resolutions: Reliability and validity of the Collaborative Interactions Scale-revised version. Psychotherapy Research, 29(3), 279-292. doi: 10.1080/10503307.2017.1414331

Doležal, P., Čevelíček, M., Řiháček, T., Roubal, J., Hytych, R., \& Ukropová, J. (2019). Why did she leave? Development of working alliance in a case of psychotherapy for depression. Research in Psychotherapy: Psychopathology, Process and Outcome, 22(2), 150-164. doi: 10.4081/ripppo.2019.354

Doran, J. M., Safran, J. D., Waizmann, V., Bolger, K., \& Muran, J. C. (2012). The Alliance Negotiation Scale: Psychometric construction and preliminary reliability and validity analysis. Psychotherapy Research, 22(6), 710-719. doi: 10.1080/ 10503307.2012.709326

Eubanks-Carter, C., Muran, J. C., Safran, J. D., \& Hayes, J. A. (2011). Interpersonal interventions or maintaining an alliance. In L. M. Horowitz \& S. Stracks (Eds.), Handbook of interpersonal psychology: Theory, research, assessment, and therapeutic interventions (pp. 519-531). Hoboken, NJ: John Wiley \& Sons.

Fernández González, O., Pérez, J. C., \& Krause, M. (2019). The relation between the therapeutic alliance and communicative intentions in therapeutic interaction during the initial phase of adolescent therapy. Research in Psychotherapy: Psychopathology, Process and Outcome, 22(2), 189-198. doi: 10.4081/ripppo.2019.356

Galvão, M. I., Silva, A. N., \& Vasco, A. B. (2019). The Alliance Negotiation Scale: Portuguese adaptation. Research in Psychotherapy: Psychopathology, Process and Outcome, 22(2), 224-232. doi: 10.4081/ripppo.2019.349

Gelso, C. J., \& Kline, K. V. (2019). The sister concepts of the working alliance and the real relationship: on their development, rupture, and repair. Research in Psychotherapy: Psychopathology, Process and Outcome, 22(2), 142-149. doi: 10.4081/ripppo.2019.373

Hendin, H., \& Cheek, J. M. (1997). Assessing hypersensitive narcissism: A reexamination of Murray's Narcism Scale. Journal of Research In Personality, 31, 588-599. doi: 10.1006/jrpe.1997.2204

Hill, C. E., Nutt-Williams, E., Heaton, K. J., Thompson, B. J., \& Rhodes, R. H. (1996). Therapist retrospective recall impasses in long-term psychotherapy: A qualitative analysis. Journal of Counseling Psychology, 43(2), 207-217. doi: 10.1037/0022-0167.43.2.207

Lingiardi, V., \& Gentile, D. (2019). The legacy of Jeremy Safran. Research in Psychotherapy: Psychopathology, 
Process and Outcome, 22(1), 1-2. doi: 10.4081/ripppo. 2019.388

Muran, J. C., Safran, J. D., Gorman, B. S., Wallner Samstag, L., Eubanks-Carter, C., \& Winston, A. (2009). The relationship of early alliance ruptures and their resolution to process and outcome in three time-limited psychotherapies for personality disorders. Psychotherapy: Theory, Research, Practice, Training, 46, 233-248. doi: 10.1037/a0016085

Muran, J. C., Safran, J. D., Samstag, L. W., \& Winston, A. (2005). Evaluating an alliance-focused treatment for personality disorders. Psychotherapy: Theory, Research, Practice, Training, 42(4), 532-545. doi: 10.1037/0033-3204.42.4.532

Muran, J. C., Segal, Z. V., Samstag, L. W., \& Crawford, C. (1994). Patient pretreatment interpersonal problems and therapeutic alliance in short-term cognitive therapy. Journal of Consulting and Clinical Psychology, 62(1), 185-190. doi: 10.1037/0022-006X.62.1.185

Oasi, O., Maggio, S., Pacella, S., \& Molgora, S. (2019). Dropout and narcissism: an exploratory research about situational factors and personality variables of the psychotherapist. Research in Psychotherapy: Psychopathology, Process and Outcome, 22(2), 165-174. doi: 10.4081/ripppo.2019.369

Safran, J. D., \& Muran, J. C. (2000). Negotiating the therapeutic alliance: A relational treatment guide. New York, NY: Guilford Press.

Safran, J. D., Muran, J. C., \& Eubanks-Carter, C. (2011). Repairing alliance ruptures. In J. C. Norcross (Ed.), Psychotherapy relationships that work (2nd ed.). New York,
NY: Oxford University Press.

Shenk, N., Zimmermann, R., Fürer, L., Krause, M., Weise, S., Kaess, M., ... Schmeck, K. (2019). Trajectories of alliance ruptures in the psychotherapy of adolescents with borderline personality pathology: timing, typology and significance. Research in Psychotherapy: Psychopathology, Process and Outcome, 22(2), 199-211. doi: 10.4081/ripppo.2019.348

Smith, P., Hilsenroth, M. J., Fiori, K. L., \& Bornstein, R. (2014). Relationship between SWAP-200 patient personality characteristics and patient-rated alliance early in treatment. The Journal of Nervous and Mental Disease, 202(5), 372-378. doi:10.1097/NMD.0000000000000134

Talia, A., Miller-Bottome, M., Wyner, R., Lilliengren, P., \& Bate, J. (2019). Patients' Adult Attachment Interview classification and their experience of the therapeutic relationship: are they associated? Research in Psychotherapy: Psychopathology, Process and Outcome, 22(2), 175-188. doi: 10.4081/ ripppo.2019.361

Tanzilli, A., Colli, A., Gualco, I., \& Lingiardi, V. (2018). Patient personality and relational patterns in psychotherapy: Factor structure, reliability, and validity of the Psychotherapy Relationship Questionnaire. Journal of Personality Assessment, 100(1), 96-106. doi: 10.1080/00223891.2016.1272050

Zalman, H., Aafjes-van Doorn, Eubanks, C. F. (2019). Alliance challenges in the treatment of a narcissistic patient: the case of Alex. Research in Psychotherapy: Psychopathology, Process and Outcome, 22(2), 212-223. doi: 10.4081/ ripppo.2019.351 